\title{
Teor de cálcio em frutos de diferentes cultivares de feijão-vagem
}

\author{
Édison Miglioranza; Ricardo de Araujo; Romeu Munashi Endo; José Roberto Pinto de Souza; Márcio \\ Adriano Montanari
}

UEL, Depto. Agronomia, C. Postal 6.001, 86051-990 Londrina-PR. E-mail: emiglior@uel.br

\begin{abstract}
RESUMO
Foi determinada a concentração de cálcio em frutos de feijãovagem cultivares: Xera, Paulista, Florence, 274, F-15, Nerina, Anseme e UEL-1, em dois experimentos, em 1997 e 1998 em Londrina. O delineamento experimental foi de blocos ao acaso com quatro repetições. Foram avaliadas as vagens classificadas como número 4 ( 8,3 a $9,4 \mathrm{~mm}$ de diâmetro). As concentrações de cálcio das cultivares foram comparadas pelo teste de Duncan a P $£ 0,05$. Nos dois anos analisados, a cultivar Xera apresentou as maiores concentrações de cálcio, média de $6,1 \mathrm{mg}$ de cálcio/g de matéria seca, enquanto que a menor concentração foi encontrada na cultivar Nerina, 4,5 mg de cálcio/g de matéria seca. Concluiu-se que o acúmulo de cálcio na vagem foi influenciado pelo genótipo da cultivar independentemente do ano agrícola estudado.
\end{abstract}

Palavras chave: Phaseolus vulgaris (L.); nutrição; alimentação, melhoramento genético.

\begin{abstract}
Calcium concentration in snap bean pods of different cultivars

The calcium concentration in the pods of several snap beans was studied in two experiments carried out in 1997 and 1998 in Londrina, Paraná state, Brazil. A randomized complete block design with four replications was used. Pods classified as number four (8.3 to $9.4 \mathrm{~mm}$ diameter) were assessed. The calcium concentrations in the cultivars Xera, Paulista, Florence, 274, F-15, Nerina, Anseme and UEL- 1 were compared by the Duncan test at $\mathrm{P} £ 0.05$. In the two years analyzed, the Xera cultivar presented the greatest calcium concentration with an average of $6.1 \mathrm{mg}$ calcium/g dry matter, while the Nerina cultivar showed the lowest concentrations with $4.5 \mathrm{mg}$ calcium/g dry matter. It was concluded that calcium accumulation in the pod was influenced by the genotype of the cultivar regardless of the agricultural year studied.
\end{abstract}

Keywords: Phaseolus vulgaris L., nutrition, breeding.

\section{(Recebido para publicação em 15 de agosto de 2001 e aceito em 08 de janeiro de 2003)}

$\mathrm{O}$ cálcio é o mineral encontrado em maior quantidade no organismo humano e a necessidade diária durante a adolescência é de $1200 \mathrm{mg} / \mathrm{dia}$ (National Reserch Council, 1989). Sua falta aumenta a probabilidade de doenças, principalmente aquelas relacionadas aos ossos como a osteosporose.

As principais fontes de cálcio para o homem são o leite e os seus derivados. Entretanto, as folhas dos vegetais constituem-se em importante fonte de cálcio, enquanto os grãos de cereais possuem baixa concentração desse elemento (Macrae et al,,1993). Dentre os principais vegetais o feijão-vagem (Phaseolus vulgaris L.) foi a terceira melhor opção como fonte de cálcio entre as 39 plantas (frutos e vegetais) analisadas (Stevens, 1974). Além disso, o cálcio presente nas vagens e nos grãos imaturos do feijão-vagem é prontamente absorvido pelo ser humano (Grusak et $a l,, 1996)$. De acordo com Filgueira (2000), o feijão-vagem apresenta $40 \mathrm{mg}$ de cálcio por $100 \mathrm{~g}$ de vagens cozidas.

A movimentação de cálcio no floema é extremamente baixa (Raven,
1977). Assim, o transporte de cálcio para a vagem é feito através do xilema devido principalmente à transpiração (Mix \& Marschner, 1976a). Até o momento, não se conhecem todos os mecanismos que regulam esse transporte. Mix \& Marschner (1976b) verificaram que o aumento da transpiração da planta inteira não aumenta necessariamente a concentração de cálcio nos frutos, pois as folhas e os frutos competem diretamente por água e cálcio.

No caso de plantas de feijão-vagem, existe baixa correlação entre a concentração no fruto e na folha (Quintana et al., 1996b). Outro fato importante é que o fruto apresenta baixa taxa de transpiração quando comparado com a da folha. Logo, o suprimento de cálcio para as vagens é limitado.

A pressão radicular pode prover suficiente concentração de cálcio para os tecidos não transpirantes como cabeça de repolho (Palzkill \& Tibbitts, 1977; Tibbitts \& Palzkill, 1979) e para frutos de morango (Bradfield \& Guttridge, 1979). No caso de feijão-vagem, não foram encontradas diferenças na concentração de cálcio na seiva (Quintana et al., 1999c). Esses pesquisadores atribuem as diferenças de concentração de cálcio nos frutos de diferentes cultivares às diferenças na taxa de fluxo do exudato.

Estudos conduzidos nos EUA mostraram que diferentes cultivares apresentaram diferentes potencialidades para o acúmulo de cálcio nos frutos (Miglioranza et al., 1997; Quintana et a., 1999d). Sabe-se, também, que é possível aumentar a concentração de cálcio nas vagens através do melhoramento genético. A herdabilidade do conteúdo de cálcio nos frutos foi estimada em 0,5 \pm 0,03 por Quintana et al. (1996b). Portanto, essa característica é provavelmente comandada por pequeno número de genes (Quintana et al., 1996b). No Brasil, ainda não se conhece a variabilidade das cultivares de feijoeiro com relação à característica de acúmulo de cálcio nas vagens.

Este trabalho teve por objetivo estudar a variação do conteúdo de cálcio em 
diferentes cultivares de feijão-vagem de hábito de crescimento determinado encontrados no mercado brasileiro, fornecendo subsídios para que os programas de melhoramento genético possam disponibilizar, num futuro próximo, cultivares com maiores concentrações desse elemento.

\section{MATERIAL E MÉTODOS}

O experimento foi conduzido em um Latossolo Vermelho eutroférrico com textura argilosa, de setembro a novembro de 1997 e 1998 em Londrina. O clima da região é Cfa, segundo a classificação de Köppen, ou seja, clima temperado (C) com chuvas bem distribuídas (f) e verões suaves (a).

Utilizaram-se cultivares comerciais de feijão-vagem com hábito de crescimento determinado. As cultivares Nerina, Xera, Paulista, Florence, 274 e F15 foram testadas no ano de 1997, e as cultivares Xera, Florence, F-15, Anseme, UEL-1, 274 e Nerina em 1998.

As sementes foram adquiridas em lojas especializadas, exceto as da cultivar UEL-1, obtidas de um lote de sementes básicas da UEL. O preparo do solo foi feito empregando-se uma aração e duas gradagens. As análises químicas dos solos apresentaram as características: $\mathrm{pH}$ em $\mathrm{CaCl}_{2}=6,0$ e 6,$2 ; \mathrm{P}=15,21$ e 16,33 $\mathrm{mg} \cdot \mathrm{dm}^{-3} ; \mathrm{Ca}=6,63$ e 7,02 $\mathrm{cmol}_{\mathrm{c}} \cdot \mathrm{dm}^{-3}$; $\mathrm{MG}=2,25$ e $2,32 \mathrm{cmol} \cdot \mathrm{dm}^{-3}$; matéria orgânica = 23,55 e 25,32 g.dm ${ }^{-3}$, em 1997 e 1998, respectivamente. Não foi verificada presença de alumínio nas amostras. Com base nestes resultados e na experiência da UEL, na condução de feijão-vagem de hábito de crescimento determinado, definiu-se a adubação de $1 \mathrm{t} /$ ha do formulado 04-14-08 na semeadura e $200 \mathrm{~kg} / \mathrm{ha}$ de sulfato de amônio aos 15 dias após a emergência (DAE). A adubação fosfatada e potássica foi feita conforme recomendação de Filgueira (2000) e adaptada para o feijão-vagem de crescimento determinado. A adubação nitrogenada foi baseada nos resultados experimentais nas áreas de condução de feijão-vagem na UEL. As sementes foram tratadas com thiabendazole, (200 $\mathrm{g}$ de produto comercial/100 kg de semente). Após o tratamento, foram realizadas as semeaduras

Tabela 1. Concentração média de cálcio nos frutos de diferentes cultivares de feijão-vagem nos anos de 1997 e 1998. Londrina, UEL, 1997 e 1998.

\begin{tabular}{lcccc}
\hline \multirow{2}{*}{ Cultivares } & \multicolumn{4}{c}{ Concentração de cálcio (mg.g- ${ }^{1}$ ) } \\
\cline { 2 - 5 } & \multicolumn{1}{c}{1997} & $\mathbf{1 9 9 8}$ \\
\hline Xera & $6,08 \mathrm{a}$ & 6,03 & $\mathrm{a}$ \\
Paulista & $5,74 \mathrm{ab}$ & - & \\
Florence & $5,57 \mathrm{ab}$ & 5,42 & $\mathrm{~b}$ \\
274 & $5,26 \mathrm{ab}$ & 4,72 & $\mathrm{C}$ \\
F-15 & $4,88 \mathrm{ab}$ & 4,78 & $\mathrm{C}$ \\
Nerina & 4,46 & $\mathrm{~b}$ & 4,37 & $\mathrm{~d}$ \\
Anseme & - & 4,74 & $\mathrm{C}$ \\
UEL-1 & - & 4,73 & $\mathrm{C}$ \\
Média & 5,30 & 4,97 & \\
\hline C.V. & 12,36 & 8,29 &
\end{tabular}

Médias seguidas de mesma letra na coluna não diferem entre si pelo teste de Duncan a 5\%.

em setembro de 1997 e 1998. A densidade populacional foi de dez plantas por metro linear. O delineamento experimental foi de blocos casualizados com quatro repetições (seis cultivares no ano de 1997 e sete em 1998). A parcela experimental foi constituída de quatro linhas de quatro metros de comprimento, espaçadas 0,40 m entre si. Como área útil considerou-se as duas linhas centrais, subtraindo-se $0,50 \mathrm{~m}$ em cada extremidade.

A irrigação suplementar foi feita por aspersão a cada duas semanas, completando-se a quantidade de água das chuvas para $25 \mathrm{~mm} / \mathrm{semana}$. O controle das plantas daninhas foi realizado por capinas manuais a cada 15 dias. A baixa incidência de pragas e doenças dispensou o uso de produtos químicos.

Para a análise do conteúdo de cálcio, foram selecionadas plantas cujas vagens coletadas foram classificadas como número quatro $(8,3$ a $9,4 \mathrm{~mm}$ de diâmetro), segundo Mullins et al. (1988). As vagens coletadas de cada cultivar foram colocadas em estufa com circulação de ar forçado à temperatura de $50-55^{\circ} \mathrm{C}$ até atingirem peso constante. Após a secagem, triturou-se o material em moinho rotativo e, posteriormente, passou-se em peneira com malha de $1 \mathrm{~mm}$. Em seguida, pesou-se três amostras de $0,40 \mathrm{~g}$ de material de cada parcela do experimento para proceder à digestão nitro-perclórica até o clareamento da amostra. Procedeu-se a diluição com água destilada e deionizada, completando-se o volume para $400 \mathrm{~mL}$. Dessa amostra, foi retirada uma alíquota homogênea para a quantificação de cálcio, mediante o emprego de espectrofotometria de absorção atômica, segundo Malavolta et al. (1997).

Os dados foram submetidos à análise de variância e a comparação entre as médias foi realizada pelo teste de Duncan a 5\% de probabilidade.

\section{RESULTADOS E DISCUSSÃO}

Na avaliação feita em 1997, o conteúdo de cálcio nos frutos das seis cultivares de feijão-vagem estudadas variou de 4,46 a 6,07 $\mathrm{mg}$ de cálcio/g de matéria seca. No ano de 1998, em sete cultivares, o conteúdo variou entre 4,37 a $6,03 \mathrm{mg}$ de cálcio/g de matéria seca (Tabela 1). Valores próximos a estes foram obtidos por Miglioranza et al. (1997), concentrações de 4,1 a 5,7 mg de cálcio/g de matéria seca de frutos de 12 cultivares de feijão vagem, e Quintana et al. (1999d) 3,82 a 6,80 mg de cálcio/ grama de matéria seca em 64 genótipos de feijão-vagem.

Os valores médios das concentrações de cálcio em frutos de feijão-vagem obtidos no presente trabalho foram 5,30 e 4,97 mg de cálcio/g de matéria seca em 1997 e 1998, respectivamente. Esses resultados estão de acordo com os obtidos por Quintana et al. (1996b) e Miglioranza et al. (1997), os quais obti- 
veram médias de 5,3 e 5,0 mg de cálcio/g de matéria seca, respectivamente. A comparação desses resultados demonstra que o acúmulo de cálcio em frutos de feijão-vagem pode ser semelhante, desde que o solo contenha suficiente quantidade do nutriente, ou seja, teor médio de $\mathrm{Ca}^{+2}=4,00 \mathrm{cmol} \cdot \mathrm{dm}^{-3}$ (IAPAR, 1994). Esses resultados corroboram àqueles encontrados por Miglioranza et al. (1997) e Quintana et al. (1999b) cuja adição de cálcio ao solo, com o intuito de aumentar o teor desse elemento para valores acima do considerado suficiente, não aumentou necessariamente o teor do mesmo nas vagens. Para estes mesmos autores, tanto a adição de sulfato de cálcio $\left(\mathrm{CaSO}_{4}\right)$ como de nitrato de cálcio $\left(\mathrm{Ca}\left(\mathrm{NO}_{3}\right)_{2}\right)$ não incrementou o conteúdo de cálcio nos frutos de feijão-vagem.

Entre as cultivares, detectou-se diferenças significativas quanto à concentração de cálcio nos frutos nos dois anos estudados. Em 1997, a cultivar Xera apresentou significativamente maior concentração de cálcio nas vagens apenas em relação à cultivar Nerina (Tabela 1). As cultivares 274, F-15, Paulista e Florence não apresentaram diferenças estatísticas entre si e, tampouco as cultivares Xera e Nerina (Tabela 1). No ano de 1998, a cultivar Xera apresentou significativamente maior concentração de cálcio do que a cultivar Florence e esta, por sua vez, foi significamente superior às cultivares F-15, Anseme, UEL-1, 274 e Nerina. Novamente, a cultivar Nerina foi a que apresentou a menor concentração de cálcio nos frutos entre todas as cultivares testadas. $O$ fato da cultivar Xera ter sido a que apresentou a maior concentração e a cultivar Nerina a que apresentou a menor concentração de cálcio nos dois anos estudados, e sendo a sequiência praticamente inalterada para as demais cultivares, evidencia que a diferença de concentração de cálcio nas vagens também é atribuída às diferenças genéticas entre as cultivares (Quintana et al.,1996b; Miglioranza et al.,1997). Essa evidência confirma a hipótese da habilidade de algumas cultivares em acumular cálcio mais eficientemente que outras (Quintana et al.,1996b).

Grusak \& Pomper (1999) demons- traram que a concentração de cálcio e a densidade estomatal são inversamente proporcionais ao incremento de diâmetros dos frutos das cultivares de feijãovagem estudadas. Todavia, para Quintana et al. (1996b), vagens com grande densidade de estômatos não apresentaram, necessariamente, maior concentração de cálcio. Estes resultados permitem concluir que a variabilidade da concentração de cálcio nas vagens, entre os genótipos de feijão-vagem pode ser atribuída às diferenças na transpiração dos frutos associadas com diferentes tamanhos dos estômatos ou com a taxa de transpiração, e não devido à diferença na densidade estomática apenas.

Os mecanismos que conduzem a diferenças na concentração de cálcio entre as cultivares não estão ainda totalmente esclarecidos. Sabe-se, contudo, que tais diferenças estão associadas às diferenças genéticas entre as cultivares e que outros fatores, além do suprimento de cálcio da solução do solo, influenciam o acúmulo do mesmo nas vagens (Quintana et al., 1996b).

Os resultados desse experimento mostraram que as diferentes cultivares possuíam habilidades diferenciadas de acumulação de cálcio nas vagens em um mesmo local e em condições edafoclimáticas semelhantes, independentemente do ano agrícola. A partir disso, conclui-se que essas cultivares podem ser utilizadas em programas de melhoramento genético vegetal com o intuito de obter, num futuro bem próximo, cultivares com maiores teores desse elemento químico.

\section{AGRADECIMENTOS}

Agradecemos ao Conselho Nacional de Desenvolvimento Científico e Tecnológico (CNPq) e à Fundação Coordenação de Aperfeiçoamento de Pessoal de Nível Superior (CAPES) pelo suporte financeiro aplicado neste trabalho científico.

\section{LITERATURA CITADA}

BRADFIELD, E.G.; GUTTRIDGE, C.G. Dependence of calcium transport and leaf tip-burn in strawberry on relative humidity and nutrient solution concentration. Annals of Botany, v. 43, n.
3, p. 363-372, 1979.

FILGUEIRA, F.A.R. Novo Manual de Olericultura. Agrotecnologia moderna na produção e comercialização de hortaliças. Viçosa: Editora UFV, 2000. 402 p.

GRUSAK, M.A.; POMPER, K.W. Influence of pod stomatal density and pod transpiration on the calcium concentration of snap bean pods. Journal of the American Society for Horticultural Science, v. 124, n. 2, p. 194-198, 1999.

GRUSAK, M.A.; PEZESHGI, S.; O'BRIEN, K.O.; ABRANS, S.A. Intrinsic ${ }^{42} \mathrm{Ca}$ labelling of green been pods for use in human biovailability studies. Journal Science Food Agronomic, v. 70, p. 11-15,1996.

IAPAR. Paraná Rural programa de desenvolvimento rural do Paraná. Manual técnico do subprograma de manejo e conservação do solo. 2. ed. SEAB, 1994. 372 p.

MACRAE, R.; ROBINSON, R.K.; SADLER, M.J. Encyclopedia of food science, food technology and nutricion, v. 1. San Diego: Academic Press, 1993. p. 585-589

MALAVOLTA, E.; VITTI, G.C.; OLIVEIRA,S.A. Avaliação do estado nutricional das plantas: princípios e aplicações. 2. ed., revisada e atualizada. Piracicaba: POTAFOS, 1997. 319 p.

MIGLIORANZA, E.; BARAK, P.; KMIECIK, K.; NIENHUIS, J. Comparasion of soil and genotypic effects on calcium concentration of snap bean pods. HortScience, v. 32, n. 1, p. 68-70, 1997.

MIX, G.P.; MARSCHNER H. Calciumgehalte in Früchten von Paprika, Bohne, Quitte und Hagebutte im Verlauf des Fruchtwachstums. Pflanzenernährung, v. 5, p. 537-549, 1976a.

MIX, G.P.; MARSCHNER, H. Einfluss exogener und endogener Faktoren auf den Calciumgehalt von Paprika und Bohnenfrüchten. Pflanzenernährung, v. 5, p. 551-563, 1976 b.

MULLINS, C.A.; STRAW, R.A.; COFFEY, D.L. Production of snap beans as affected by soil tillage method and row spacing. Journal of American Society for Horticultural Science, v. 113, n. 5, p. 667-669, 1988.

NATIONAL RESEARCH COUNCIL (USA). Recommended dietary allowances, $10^{\text {th }} \mathrm{ed}$. Food and Nutricion Board, Commission on Life Sciences. Washington DC: National Academy Press, 1989. 284 p.

PALZKILL, D.A.; TIBBITTS, T.W. Evidence that root pressure flow is required for calcium transport to head leaves of cabbage. Plant Physiology, v. 60, n. 6, p. 854-856, 1977.

QUINTANA, J.M.; HARRISON, H.C.; NIENHUIS, J.; PALTA, J.P.; KMIECIK, K. Differences in pod calcium concentration for eight snap bean and dry bean cultivars. HortScience, v. 34, n. 5, p. 932-934, 1999a.

QUINTANA, J.M.; HARRISON, H.C.; PALTA, J.P.; NIENHUIS, J.; KMIECIK, K. Calcium fertilizers fail to affect pod calcium concentration and yield of four snap bean cultivars. HortScience, v. 34, n. 4, p. 646-647, 1999 b.

QUINTANA, J.M.; HARRISON, H.C.; PALTA, J.P.; NIENHUIS, J.; KMIECIK, K.; MIGLIORANZA, E. Xylem flow rate differences are associated with genetic variation in snap bean pod calcium concentration. Journal of American Society for Horticultural Science, v. 124, n. 5, p. 
488-491, 1999c.

QUINTANA, J.M.; HARRISON, H.C.; NIENHUIS, J.; PALTA, J.P.; KMIECIK, K.; MIGLIORANZA, E. Comparison of pod calcium concentration between two snap bean populations. Journal of American Society for Horticultural Science, v. 124, n. 3, p. 273-276, 1999d.

QUINTANA, J.M.; HARRISON H.C.; NIENHUIS J.; PALTA, J.P. Evaluation of stomatal density and calcium concentration on pods of six commercial cultivars of snap beans (Phaseolus vulgaris L.) at four planting dates. Resumo 165, HortScience, v. 31, n. 4, p. 593, 1996 a.

QUINTANA,
NIENHUIS, J.; PALTA J.P.; GRUSAK, M.A. Variation in calcium concentration among sixty $\mathrm{S}_{1}$ families and four cultivars of snap bean (Phaseolus vulgaris L.). Journal of American Society for Horticultural Science, v. 121, n. 5, p. 789-793. 1996b.

RAVEN, J.A. $\mathrm{H}^{+}$and $\mathrm{Ca}^{+2}$ in phloem and symplast: relation of relative immobility of the íns to the cytoplasmic nature of the transport paths. New Phytologyst, v. 79, p. 465-480, 1977.

STEVENS, M.A. Varietal influence on nutritional value. In: WHITE, P.L. \& SELVEY, N. (ed.)
Nutritional quality of fresh fruits and vegetables. New York: Futura Publishing, 1974. p. 87-110.

TIBBITTS, T.W.; PALZKILL, D.A. Requirement for root pressure flow to provide adequate calcium to low transpiring tissue. Communications in Soil Science and Plant Analysis. v. 10, p. 251-257, 1979. 